\title{
Second Promised Land: Migration to Alberta and the Transformation of Canadian Society
}

\author{
by Harry H. Hiller \\ Kingston and Montreal: McGill-Queens University Press 2009 \\ ISBN 9780773535268 \\ Softcover, C\$29.95, 568 pp.
}

\author{
Reviewed by Karen King \\ The Martin Prosperity Institute, Joseph L. Rotman School of Management, University of Toronto \\ karen.king@rotman.utoronto.ca
}

Harry Hiller's Second Promised Land provides insight into the migration experience to Alberta through an in-depth exposition of Canadian internal migration stories. The book focuses on the period between 1996 and 2002, a time when Alberta's economy was expanding and on the verge of booming. Hiller unpacks the complexity of the migration decisions and processes of Alberta's migrants through a recounting of the individual migration experience, supported by statistical data and analysis. The interweaving of these interviews gives the reader a greater understanding of the motivations and drivers behind the choice to move to Alberta. In particular, these interviews highlight the reasons why and how Alberta has become the "second promised land" for many in Canada.

Hiller's book begins with an overview of how Alberta's circumstances and position within Canada have led to an important internal migration flow into Alberta. The historical importance of the west and the prairie provinces is discussed in detail, which provides important context to the understanding of Alberta's emergence as a migration destination. It is the economic transformation of Alberta and its metropolitan areas over the decades that has made Alberta an important destination in Canada. The book then moves onto the new wave of migration in 1996, when Alberta began to once again have a positive inflow of migrants compared to the negative flows of the previous thirteen years, with the primary destination choices being the large metropolitan areas of Calgary and Edmonton. The emergence of Alberta as an economic power is discussed as a result of the evolution of its oil and gas industries. However, as Hiller points out, it was not only the emergence of the oil and gas industries but the multiplier effects in other sectors, such as the service-producing sector, that helped propel Alberta's economy.

Following this, Hiller discusses the migration decision as a process. Of particular importance is the discussion of the decision to make the choice to migrate. Interviews are used to highlight the myriad of reasons individuals had for making the choice to move from their respective homes to Alberta. The discussion then moves into the importance of place, and what the term place may encompass, as well as the making of home. Hiller not only focuses on the reasons for moving to Alberta, but why migrants chose to leave their places of residence. It is here that the in-depth interviews particularly shine, as the narratives of these migrants highlight their individual reasons for leaving. Next, the discussion turns to Alberta as a destination. Narratives discussing the migration stream are particularly interesting, highlighting how many connections were to be had, or made, by migrants to Alberta. These connections to migrants' origins made adapting to their new lives in Alberta easier.

Hiller's book goes beyond simply a discussion of the internal migration decisions and motivations that drew people to Alberta. A broad range of topics related to migration are covered in the Albertan context. One chapter discusses the topic of women and migration. With these interviews, Hiller highlights the dynamics of the migration decision, as well as the role of women once the migration has taken place. Another such chapter focuses on the relationship between computers (including the internet) and the migration process. 
Finally, Hiller addresses the idea of return, and the effect of the out-migration on origin communities. As the decision to move to Alberta is complex, the decision to return is just as complex. For some migrants, Alberta is viewed as a temporary place of residence before a return "home." Returning to one's place of origin yields different results, with some being able to capitalize on their experiences in Alberta, while others are less able to do so.

Hiller's Second Promised Land is a valuable contribution to our understanding of internal migration in Canada. The book provides an in-depth look not only at migration patterns in Alberta and Canada, but also at its processes, motivators, and consequences. 